OPEN ACCESS

Edited by:

Michael C. Carroll,

Boston Children's Hospital and

Harvard Medical School, USA

Reviewed by:

Masahide Tone,

Cedars-Sinai Medical Center, USA

Matthew Cook,

Canberra Hospital and Australian

National University, Australia

*Correspondence:

Seppo Mer

seppo.meri@helsinki.fi

Specialty section:

This article was submitted to

Immunological Tolerance,

a section of the journal

Frontiers in Immunology

Received: 02 November 2015

Accepted: 22 February 2016

Published: 08 March 2016

Citation:

Reichhardt MP and Meri S (2016)

SALSA: A Regulator of the Early Steps of Complement Activation on

Mucosal Surfaces.

Front. Immunol. 7:85.

doi: 10.3389/fimmu.2016.00085

\section{SALSA: A Regulator of the Early Steps of Complement Activation on Mucosal Surfaces}

\author{
Martin Parnov Reichhardt and Seppo Meri* \\ Immunobiology Research Program, Research Programs Unit, Department of Bacteriology and Immunology, Haartman \\ Institute, University of Helsinki, Helsinki, Finland
}

Complement is present mainly in blood. However, following mechanical damage or inflammation, serous exudates enter the mucosal surfaces. Here, the complement proteins interact with other endogenous molecules to keep microbes from entering the parenteral tissues. One of the mucosal proteins known to interact with the early complement components of both the classical and the lectin pathway is the salivary scavenger and agglutinin (SALSA). SALSA is also known as deleted in malignant brain tumors 1 and gp340. It is found both attached to the epithelium and secreted into the surrounding fluids of most mucosal surfaces. SALSA has been shown to bind directly to C1q, mannose-binding lectin, and the ficolins. Through these interactions SALSA regulates activation of the complement system. In addition, SALSA interacts with surfactant proteins $A$ and D, secretory $\lg A$, and lactoferrin. Ulcerative colitis and Crohn's disease are examples of diseases, where complement activation in mucosal tissues may occur. This review describes the latest advances in our understanding of how the early complement components interact with the SALSA molecule. Furthermore, we discuss how these interactions may affect disease propagation on mucosal surfaces in immunological and inflammatory diseases.

Keywords: gp340, DMBT1, Crohn's disease, ficolins, MBL, C1q, ulcerative colitis, IBD

\section{INTRODUCTION}

Activation of the complement system is strongly involved in generating inflammation, combatting microbial infections, and participating in clearance of non-viable tissue. Although complement is present mainly in blood, it is also found in serous exudates on mucosal surfaces, such as in the oral cavity or the airways $(1,2)$. This is particularly seen after mechanical, infectious, or immune damage, e.g., in periodontal disease or SLE (3). When serous exudates enter the mucosal surfaces, innate immune proteins interact with mucosal surface proteins. Together, these molecules participate in clearance and defense against invading microorganisms. Although bleeding at the mucosal surfaces is observed daily, even in healthy individuals, the role of the complement system in this environment has so far been studied very little. Of particular interest would be the need to suppress complementmediated inflammation, while still mediating the antimicrobial defense functions. 


\section{Salivary Scavenger and Agglutinin}

One of the molecules at the mucosal surfaces that interact with the early complement components is a protein that we named salivary scavenger and agglutinin (SALSA) (4-7). SALSA, also known as gp340, "deleted in malignant brain tumors 1" (DMBT1), and salivary agglutinin (SAG), was first described as a $300-400 \mathrm{kDa}$ streptococcus agglutinating agent from saliva (8-10). Subsequently, SALSA has been suggested to function in epithelial homeostasis, innate immunity, inflammation, and tumor suppression (11-13). Many of these functions are mediated through interactions with endogenous ligands. SALSA has been shown to bind the complement components C1q, mannose-binding lectin (MBL), and the ficolins $(4,6)$. Furthermore, SALSA has been found to interact with surfactant proteins $\mathrm{A}$ and $\mathrm{D}$ ( $\mathrm{SpA}$ and $\mathrm{SpD}$, respectively), secretory IgA, lactoferrin, fibrin/fibrinogen, trefoil factors, and mucin-5B (Table 1) (9, 14-19). The multiple binding partners suggest that SALSA plays a central role in regulating inflammation and immune responses on mucosal surfaces.

\section{SALSA in Antimicrobial Defense}

Salivary scavenger and agglutinin is expressed at most mucosal surfaces, including the lungs, oral cavity, gastrointestinal tract, and vagina (31-35). It has been found both attached to the epithelium and secreted into the lining fluids, such as saliva, tear fluid, and respiratory mucosal secretions $(8,9,14,36)$. Recent studies detected SALSA in the amniotic fluid and in the intestines of neonates (37). SALSA was estimated to constitute up to $10 \%$ of the total protein amount in meconium and in the saliva of young

TABLE 1 | Endogenous and microbial ligands of SALSA.

\begin{tabular}{ll}
$\begin{array}{l}\text { Endogenous } \\
\text { ligand }\end{array}$ & Suggested functional relevance \\
\hline C1q & Complement regulation (4) \\
MBL & Complement regulation (6) \\
Ficolins & Complement regulation (6) \\
SpD & Microbial agglutination (9) \\
SpA & Microbial agglutination (16) \\
IgA & Microbial agglutination (8) \\
Lactoferrin & Bacterial binding (20) \\
DNA & Inflammation (21) \\
Heparan sulfate & Inflammation (21) \\
Trefoil factors & Tissue homeostasis (17) \\
MUC5B & Microbial agglutination (22) \\
Fibrin & Not known (19) \\
Fibrinogen & Not known (19) \\
Erythrocytes & Aggregation (19) \\
Platelets & Aggregation (19) \\
\hline Microbe & Specific strains \\
\hline Streptococcus & S. pyogenes, S. agalactiae, S. pneumonia, S. mutans, S. mitis, \\
& S. oralis, S. salivarius, S. gordonii, S. crista, S. parasanguinis, \\
Siruses & S. vestibularis, S. intermedius, S. anginosus, S. suis (7, 23-25) \\
Lactobacillus & L. rhamnosus, L. casei, L. reuteri, L. lactis (26) \\
Other bacteria & Staphylococcus aureus, Bifidobacterium, Actinomyces, \\
& Salmonella enterica serovar Typhimurium, Helicobacter pylori, \\
Haemophilus influenzae, Klebsiella oxytoca (23-28)
\end{tabular}

The listed ligands have been found to bind either human SALSA, the murine-ortholog of SALSA, or the recombinantly expressed bacterial-binding peptide, SRCRP2. children ( $<3$ years), making it one of the most abundant proteins in these environments $(37,38)$.

On the mucosal surfaces, SALSA has been shown to regulate the local immune system. On one hand, it scavenges invading microorganisms, whereas, on the other hand, it interacts with the mucosal epithelium to improve the integrity of this physical barrier (Figure 1A) $(13,39)$. SALSA binds a broad range of microbes, including viruses and bacteria (Table 1). Studies have shown that SALSA in the oral and intestinal mucosal secretions is sufficient to suppress infection by agglutinating microorganisms and keeping them from infecting the tissue. This has been observed for Salmonella enterica, HIV-1, and influenza A-virus (IAV) (27, 29, $30,40)$. These studies suggested that SALSA simply functioned by agglutinating the microbes. However, the role of SALSA appears to be more complex than that. SALSA binds, e.g., to epithelial and tooth surfaces in addition to being secreted into the fluid phase (23). The epithelium-attached localization of a protein with a solely bacteria-agglutinating function would not appear to be beneficial for the human host. This paradox has been made clear by studies showing that SALSA, in some cases, may actually be exploited by the invading microbes. A study of dental caries showed that certain variants of the SALSA protein correlated positively with Streptococcus mutans adhesion to SALSA-coated hydroxyapatite surfaces and the development of dental caries. Other SALSA variants displayed the opposite correlation (41). In the case of HIV-1 infection, the salivary fluid SALSA protein was found to interfere with oral transmission. However, SALSA expressed on the vaginal epithelium had an enhancing effect on the infectivity of the virus (35). These findings suggest that some microbes have evolved mechanisms to utilize SALSA to infect the human body.

\section{Isoforms of the SALSA Protein}

As indicated above, various variants of SALSA may interact differently with microbes. Indeed, different SALSA isoforms have been identified on various mucosal surfaces. These have been shown to vary both in protein sequence and in the glycosylation patterns $(23,36,37)$. The gene for SALSA (in chromosome 10q26.13) encodes 13 highly conserved scavenger receptor cysteine-rich (SRCR) domains. These 109-amino acid-long motifs are found as "pearls on a string" separated by SRCR interspersed domains (SIDs) (Figure 1B). The stretch of 13 SRCR domains is followed by $2 \mathrm{C} 1 \mathrm{r} / \mathrm{C} 1 \mathrm{~s}$, urchin embryonic growth factor and bone morphogenetic protein-1 (CUB) domains encompassing the 14th SRCR domain. Finally, a zona pellucida (ZP) domain is found at the most C-terminal end $(31,42)$. The repetitive sequence of SRCR domains may facilitate alternative splicing (43). Indeed, mRNA transcripts encoding between 8 and 13 of the N-terminal SRCR domains have been observed, all in all revealing up to 7 distinct alleles $(31,42,44)$. It has been estimated that SALSA contains $25-45 \%(\mathrm{w} / \mathrm{w})$ of carbohydrate $(8,31)$. SALSA contains all the major sugar components. However, differences have been found to correlate to the secretor $[\mathrm{Se}(+/-)]$ status ( \pm expression of the $\alpha 1-2$ fucosyl-transferase). The blood group antigens, ABO, and Lewis antigens $b$ and $y\left(\mathrm{Le}^{\mathrm{b}}\right.$ and $\left.\mathrm{Le}^{\mathrm{y}}\right)$ were found on SALSA from $\mathrm{Se}(+)$ individuals. In contrast, SALSA from $\mathrm{Se}(-)$ individuals did not contain $\mathrm{ABO}, \mathrm{Le}^{\mathrm{b}}$ nor $\mathrm{Le}^{\mathrm{y}}$ antigens. Instead, Lewis antigens a 


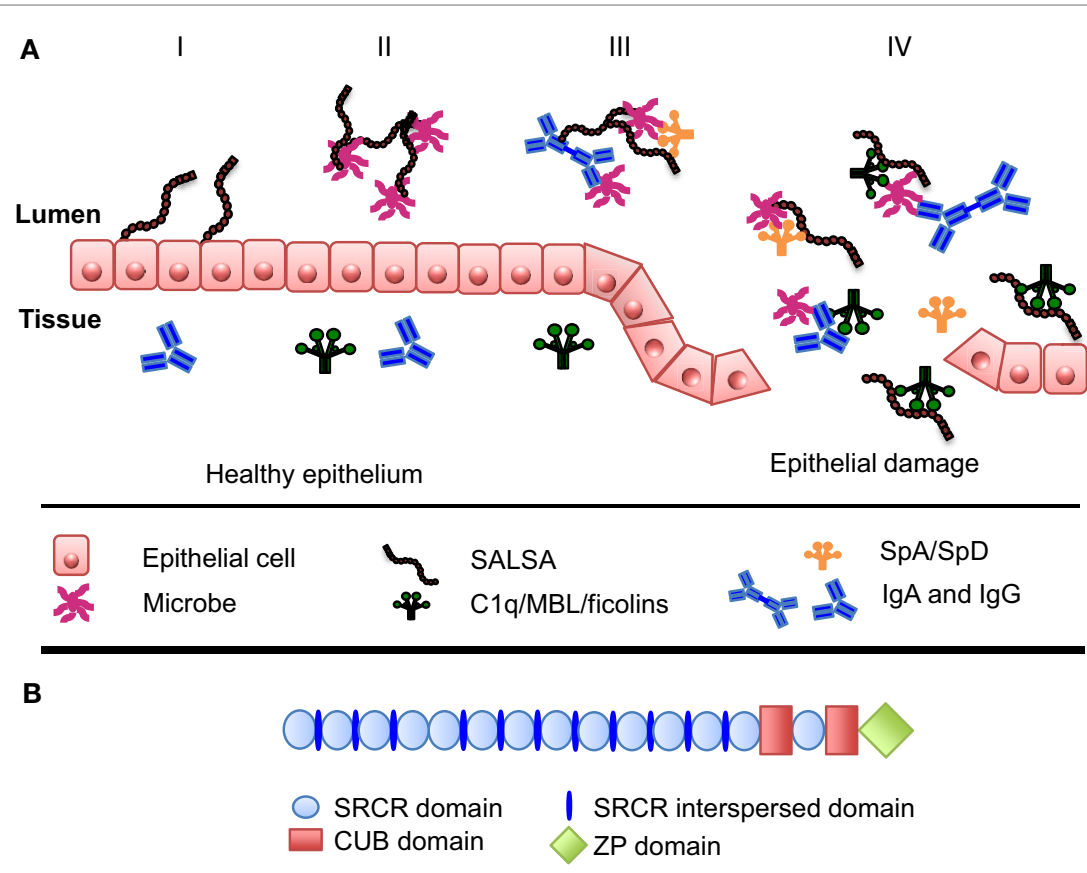

FIGURE 1 | Function and structure of SALSA at the mucosal surfaces. (A) At the mucosal surfaces, the SALSA protein is mainly found associated with the epithelium and secreted into the surrounding fluids. The known features and functions of SALSA are presented in four panels (I-IV). (I) SALSA is present on the epithelial cell surface and deposited in the extracellular matrix, where it is involved in maintaining epithelial homeostasis. (II) Fluid-phase SALSA binds a broad array of microbes. It has been shown to agglutinate viruses, as well as both Gram-positive and Gram-negative bacteria thus preventing them from invading the parenteral spaces. (III) SALSA interacts with other endogenous molecules present at the mucosal surfaces, such as surfactant proteins SpA and SpD as well as IgA. It is believed that these molecules cooperate in antimicrobial defense. (IV) In the case of epithelial damage, cells and molecules from the tissue become mixed with the luminal contents. In this context, SALSA may bind the complement sensor molecules C1q, MBL, and the ficolins, thereby SALSA could initiate complement activation against distinct microbes or participate in the clearance of injured tissue components. (B) In its molecular structure, SALSA contains a stretch of 13 scavenger receptor cysteine-rich (SRCR) domains separated by SRCR interspersed domains. These are followed by two C1r/C1s, urchin embryonic growth factor and bone morphogenetic protein-1 (CUB) domains surrounding the 14th SRCR domain. Finally, a zona pellucida (ZP) domain is found at the most C-terminal end of the protein.

and $\mathrm{x}\left(\mathrm{Le}^{\mathrm{a}}\right.$ and $\left.\mathrm{Le}^{\mathrm{x}}\right)$ were present $(45,46)$. Thus, different forms of the SALSA protein exist. They are produced both by variations in the protein chain and in the extent and nature of glycosylation. The SALSA protein composition varies not only between individuals but also in different body compartments within the same individual $(23,36,37)$.

\section{SALSA AND COMPLEMENT}

\section{Interactions of C1q, MBL, and Ficolins with SALSA}

C1q, MBL, and ficolins all form bouquet-like structures, where each subunit contains a collagen-like domain (stalk) and a carboxyterminal globular domain (the "flower") $(47,48)$. C1q binds specifically to surface-attached IgG and IgM. However, other endogenous non-immunoglobulin ligands have been found, including SALSA $(4,6)$. Also, MBL, M-ficolin, H-ficolin, and L-ficolin were found to bind to SALSA (6). All interactions between SALSA and the complement molecules were calcium dependent.

C1q was shown to bind SALSA through the globular domain in a region close to the immunoglobulin-binding site (49). Similarly, it appears that MBL utilizes the globular carbohydrate recognition domain (CRD) for the interaction with SALSA. Due to the heavy glycosylation of SALSA, sugar structures may function as a target for the CRD of MBL $(8,31)$. When the binding of MBL was tested to SALSA purified from the saliva of a single donor up to $60 \%$ inhibition of the SALSA-MBL interaction was observed when $5 \mathrm{mM}$ fucose was added to the fluid phase (7). MBL binds to the Le ${ }^{\mathrm{b}}$ antigen, a fucose-containing oligosaccharide (7). A clear difference was observed in the binding of MBL to SALSA from secretors vs. non-secretors (7). This correlates to the finding that only SALSA from $\mathrm{Se}(+)$ individuals contains the Le $\mathrm{e}^{\mathrm{b}}$ antigen (45, 46). This strongly suggests that MBL binds via the CRD to the Le $\mathrm{b}^{\mathrm{b}}$ antigen of SALSA.

\section{Complement Activation and Regulation by SALSA}

It has been shown that the binding of C1q to SALSA is sufficient to initiate activation of the classical complement activation pathway $(4,6)$. In addition, SALSA was shown to influence the activation of the lectin pathway through interactions with MBL and the ficolins $(5,6)$. The overall outcome of SALSA-mediated complement regulation varies with the specific location of SALSA (6). SALSA coated onto a microtiter plate surface activated complement as 
measured by deposition of $\mathrm{C} 4 \mathrm{~b}$ and $\mathrm{C} 3 \mathrm{~b}$ after incubation with normal human serum (NHS). Using MBL-deficient serum, approximately $30 \%$ of the total complement activation was lost (6). The residual activation is likely mediated by $\mathrm{Clq}$ and possibly also by the ficolins $(4,6)$. In contrast to complement activation observed by surface-bound SALSA, SALSA in the fluid phase caused a dose-dependent inhibition of the lectin pathway (6). No such effect was observed on the classical pathway, which may be due to the almost 100 times higher concentrations of C1q vs. MBL. SALSA was able to interfere with the binding of the MBL-MASP2 complex to surface-coated mannan. Candida albicans is a known target for MBL-mediated complement activation. When NHS was mixed with increasing concentrations of SALSA and incubated with C. albicans a dose-dependent inhibition of the deposition of both $\mathrm{C} 4 \mathrm{~b}$ and $\mathrm{C} 3 \mathrm{~b}$ was observed on the Candida surface (6). The dual effects of SALSA on the complement system appear contradictory at first glance. On one hand, by binding to $\mathrm{MBL}$ and ficolins in the fluid phase, SALSA can prevent their binding to targets. On the other hand, when bound to a surface, SALSA can direct complement activation against appropriate targets, such as microbes. Overall, it appears that SALSA is a mucosal first line recognition molecule that can distinguish between targets to be cleared vs. structures to be tolerated.

Increased SALSA expression may alone and in concert with, e.g., $\mathrm{Clq}$ and MBL, lead to increased microbial clearance. In addition to the interactions with the complement proteins, SALSA can also mediate its anti-bacterial and inflammation regulating functions through interactions with $\operatorname{IgA}, \operatorname{SpA}$, and $\operatorname{SpD}(8,9,16)$. The functional outcome of these interactions is a cooperative effect on the microbial agglutination (Figure 1A) (50,51). SALSA, $\mathrm{SpA}$, and $\mathrm{SpD}$ have a dual effect against IAV: viral agglutination and inflammatory modulation (52). The binding of the SALSA ligand $\mathrm{SpD}$ to IAV has been shown to induce a strong respiratory burst response in neutrophils in vitro. This response was reduced by the addition of SALSA (51). It has been suggested that this allows a regulated response by the neutrophils, with an increased uptake of IAV but without an excessive and potentially harmful burst response (13). A similar feature is observed in the case of $\mathrm{C}$-reactive protein and the other pentraxins. They target $\mathrm{C} 1 \mathrm{q}$ to apoptotic and necrotic tissue, while simultaneously recruiting factor $\mathrm{H}$ to limit the complement activation $(53,54)$. This process is relevant during the removal of apoptotic debris at the mucosal surfaces, as well (55). The differential outcome of the interaction of SALSA with complement may represent a similar balanced effector mechanism against invading microbes.

\section{SALSA AND COMPLEMENT IN INFLAMMATORY BOWEL DISEASE}

Intestines are one of the primary sites, where an imbalance between activation and control of immune responses leads to disease. Inflammatory bowel disease (IBD) encompasses two chronic relapsing and remitting inflammatory conditions of the gastrointestinal tract. These are known as ulcerative colitis (UC) and Crohn's disease (CD). Together, they affect up to 1:250 in the adult population (56). In children, the incidence of IBD is on the rise. Disease onset is during childhood or adolescence for up to $25 \%$ of the patients; although the mortality of the disease has been declining, it has a major impact on the development of these young individuals (57). The fundamental causes of the diseases are still obscure.

Several associations have been found between complement components and IBD. Specifically for the gut mucosa, the development of CD has been associated with an altered expression of components of the lectin pathway. The frequency of the $M B L 2$ gene allele, which results in MBL deficiency, was significantly elevated in pediatric patients with CD compared to healthy controls or adults with Sjögren's syndrome $(58,59)$. Deficiencies in classical and alternative pathway components are rarer. Some patients deficient in $\mathrm{C} 1$ inhibitor, which is commonly associated with hereditary angioedema, were found to develop non-infectious enteritits and IBD (60-62). To further highlight an involvement of the classical and lectin pathways of complement, we recently observed an association of pediatric IBD to an MHC haplotype that involves a deficiency of two C4 genes (HLA-A03; HLA-B07; one C4A gene; one C4B gene; HLA-DRB115) (63).

A study of lectin pathway components during CD treatment found a dramatic impact on M-ficolin and MASP-3 levels in patients responding to anti-TNF- $\alpha$ therapy (64). However, how the complement components specifically affect the local inflammatory environment of the gut is not clear yet. The above described interactions with the SALSA molecule present a potential way for complement to affect a balanced mucosal immunological response. Current models of $\mathrm{CD}$ pathogenesis include an altered response to the local microbiota, and an increased SALSA expression has been linked to several of these responses (65). Studies have shown that SALSA can be strongly induced by various immunological stimuli $(66,67)$. The increased levels of SALSA in the intestinal epithelium of patients with IBD and in the ethmoid sinusoidal mucosa of patients with chronic sinusitis suggest that SALSA expression is part of the mucosal inflammatory response (66-68). Furthermore, a study of preterm infants revealed that an increase in the pulmonary SALSA levels was part of the mucosal response to neonatal infection (69).

Salivary scavenger and agglutinin expression by the intestinal epithelium is induced by NOD2 and TLR4 activation (27). However, the outcome of an induced SALSA expression during IBD may not necessarily lead to enhanced clearance only. Rather, the interaction of SALSA with several endogenous molecules may be part of an efficient but limited immunological response. Failure in these processes could propagate an unbalanced and overactive local immune response in IBD. It has been shown that the previously described SALSA isoforms influence both the interaction with microbes and the endogenous ligands, such as $\operatorname{IgA}, \mathrm{C} 1 \mathrm{q}$, and MBL (37). Interestingly, the specific bacterial-binding ability of SALSA has been found to depend not only on the isoform of the protein but also on the location of the protein. Fluid-phase SALSA can bind and aggregate some streptococcal strains, while SALSA coated to a hydroxyapatite surface does not (23). Thus, the association with the mucosal epithelium or the secretion into the lining fluids may further affect the local immunological environment differently. Finally, the described interaction of SALSA and trefoil factors, being important in maintaining the 
mucosal epithelial barrier, has also been suggested to play a role in $\operatorname{IBD}(70,71)$.

Salivary scavenger and agglutinin may be part of the normal immunological response of the mucosal epithelium during infection. Individual variations in the expression of SALSA isoforms alternate the ability of SALSA to interact with endogenous ligands, to invade microbes, and perhaps even to induce a limited burst response in neutrophils. It is therefore not surprising that a specific SALSA isoform, lacking the five most N-terminal SRCR domains, has been associated with $\operatorname{CD}(65,67)$.

We speculate that the individual variations in the SALSA interactions are key in understanding how this molecule could play a role in shifting the immunological balance toward increased inflammation at the mucosal surfaces, with detrimental effects for IBD patients.

\section{FUTURE PERSPECTIVES}

At the mucosal surfaces, a very tight immunological response to infection and inflammation is essential. The SALSA molecule is central player interacting with a multitude of endogenous molecules, invading microbes and the epithelial barrier. Due to the tightly linked interactions, a balanced function of the SALSA molecule is key in avoiding an overactive immune response. The interplay between the various SALSA isoforms, ficolins, $\mathrm{MBL}$, and $\mathrm{C1q}$ with modified tissue components, carbohydrates, acetylated molecules, and microbes on mucosal surfaces provides an interesting area for future research that may open a new understanding of mechanisms underlying the development of mucosal immunological disorders.

\section{AUTHOR CONTRIBUTIONS}

Both authors contributed to the design and writing of this review.

\section{FUNDING}

This work was supported by the Helsinki Biomedical Graduate Program, the Jenni and Antti Wihuri foundation, Helsinki University Central Hospital funds (EVO), the Sigrid Jusélius Foundation, Signe and Ane Gyllenberg Foundation, Magnus Ehrnrooth Foundation, Helsinki University Funds, the Stockmann Foundation, and the Academy of Finland.

\section{REFERENCES}

1. Boackle RJ. The interaction of salivary secretions with the human complement system - a model for the study of host defense systems on inflamed mucosal surfaces. Crit Rev Oral Biol Med (1991) 2:355-67.

2. Persson CG, Erjefalt I, Alkner U, Baumgarten C, Greiff L, Gustafsson B, et al. Plasma exudation as a first line respiratory mucosal defence. Clin Exp Allergy (1991) 21:17-24. doi:10.1111/j.1365-2222.1991.tb00799.x

3. Courts FJ, Boackle RJ, Fudenberg HH, Silverman MS. Detection of functional complement components in gingival crevicular fluid from humans with periodontal diseases. J Dent Res (1977) 56:327-31. doi:10.1177/0022034577 0560032001

4. Boackle RJ, Connor MH, Vesely J. High molecular weight non-immunoglobulin salivary agglutinins (NIA) bind C1Q globular heads and have the potential to activate the first complement component. Mol Immunol (1993) 30:309-19. doi:10.1016/0161-5890(93)90059-K

5. Leito JT, Ligtenberg AJ, van Houdt M, van den Berg TK, Wouters D. The bacteria binding glycoprotein salivary agglutinin (SAG/gp340) activates complement via the lectin pathway. Mol Immunol (2011) 49:185-90. doi:10.1016/j. molimm.2011.08.010

6. Reichhardt MP, Loimaranta V, Thiel S, Finne J, Meri S, Jarva H. The salivary scavenger and agglutinin binds MBL and regulates the lectin pathway of complement in solution and on surfaces. Front Immunol (2012) 3:205. doi:10.3389/ fimmu.2012.00205

7. Gunput ST, Ligtenberg AJ, Terlouw B, Brouwer M, Veerman EC, Wouters D. Complement activation by salivary agglutinin is secretor status dependent. Biol Chem (2015) 396:35-43. doi:10.1515/hsz-2014-0200

8. Ericson T, Rundegren J. Characterization of a salivary agglutinin reacting with a serotype c strain of Streptococcus mutans. Eur J Biochem (1983) 133:255-61. doi:10.1111/j.1432-1033.1983.tb07456.x

9. Holmskov U, Lawson P, Teisner B, Tornoe I, Willis AC, Morgan C, et al. Isolation and characterization of a new member of the scavenger receptor superfamily, glycoprotein-340 (gp-340), as a lung surfactant protein-D binding molecule. J Biol Chem (1997) 272:13743-9. doi:10.1074/jbc.272.21.13743

10. Mollenhauer J, Wiemann S, Scheurlen W, Korn B, Hayashi Y, Wilgenbus KK, et al. DMBT1, a new member of the SRCR superfamily, on chromosome 10q25.3-26.1 is deleted in malignant brain tumours. Nat Genet (1997) 17:32-9. doi:10.1038/ng0997-32

11. Kang W, Reid KB. DMBT1, a regulator of mucosal homeostasis through the linking of mucosal defense and regeneration? FEBS Lett (2003) 540:21-5. doi:10.1016/S0014-5793(03)00217-5

12. Ligtenberg AJ, Veerman EC, Nieuw Amerongen AV, Mollenhauer J. Salivary agglutinin/glycoprotein-340/DMBT1: a single molecule with variable composition and with different functions in infection, inflammation and cancer. Biol Chem (2007) 388:1275-89. doi:10.1515/BC.2007.158

13. Madsen J, Mollenhauer J, Holmskov U. Review: gp-340/DMBT1 in mucosal innate immunity. Innate Immun (2010) 16:160-7. doi: $10.1177 / 1753425910368447$

14. Thornton DJ, Davies JR, Kirkham S, Gautrey A, Khan N, Richardson PS, et al. Identification of a nonmucin glycoprotein (gp-340) from a purified respiratory mucin preparation: evidence for an association involving the MUC5B mucin. Glycobiology (2001) 11:969-77. doi:10.1093/glycob/11.11.969

15. Rundegren J, Arnold RR. Differentiation and interaction of secretory immunoglobulin A and a calcium-dependent parotid agglutinin for several bacterial strains. Infect Immun (1987) 55:288-92.

16. Tino MJ, Wright JR. Glycoprotein-340 binds surfactant protein-A (SP-A) and stimulates alveolar macrophage migration in an SP-A-independent manner. Am J Respir Cell Mol Biol (1999) 20:759-68. doi:10.1165/ajrcmb.20.4.3439

17. Thim L, Mortz E. Isolation and characterization of putative trefoil peptide receptors. Regul Pept (2000) 90:61-8. doi:10.1016/S0167-0115(00)00110-5

18. Oho T, Bikker FJ, Nieuw Amerongen AV, Groenink J. A peptide domain of bovine milk lactoferrin inhibits the interaction between streptococcal surface protein antigen and a salivary agglutinin peptide domain. Infect Immun (2004) 72:6181-4. doi:10.1128/IAI.72.10.6181-6184.2004

19. Muller H, Renner M, Helmke BM, End C, Weiss C, Poeschl J, et al. Deleted in malignant brain tumors 1 is up-regulated in bacterial endocarditis and binds to components of vegetations. J Thorac Cardiovasc Surg (2009) 138:725-32. doi:10.1016/j.jtcvs.2009.05.021

20. Mitoma M, Oho T, Shimazaki Y, Koga T. Inhibitory effect of bovine milk lactoferrin on the interaction between a streptococcal surface protein antigen and human salivary agglutinin. J Biol Chem (2001) 276:18060-5. doi:10.1074/jbc.M101459200

21. End C, Bikker F, Renner M, Bergmann G, Lyer S, Blaich S, et al. DMBT1 functions as pattern-recognition molecule for poly-sulfated and poly-phosphorylated ligands. Eur J Immunol (2009) 39:833-42. doi:10.1002/eji.200838689

22. Wickstrom C, Christersson C, Davies JR, Carlstedt I. Macromolecular organization of saliva: identification of 'insoluble' MUC5B assemblies and 
non-mucin proteins in the gel phase. Biochem J (2000) 351(Pt 2):421-8. doi:10.1042/bj3510421

23. Loimaranta V, Jakubovics NS, Hytonen J, Finne J, Jenkinson HF, Stromberg N. Fluid- or surface-phase human salivary scavenger protein gp340 exposes different bacterial recognition properties. Infect Immun (2005) 73:2245-52. doi:10.1128/IAI.73.4.2245-2252.2005

24. Prakobphol A, Xu F, Hoang VM, Larsson T, Bergstrom J, Johansson I, et al. Salivary agglutinin, which binds Streptococcus mutans and Helicobacter pylori, is the lung scavenger receptor cysteine-rich protein gp-340.J Biol Chem (2000) 275:39860-6. doi:10.1074/jbc.M006928200

25. Madsen J, Tornoe I, Nielsen O, Lausen M, Krebs I, Mollenhauer J, et al. CRP-ductin, the mouse homologue of gp-340/deleted in malignant brain tumors 1 (DMBT1), binds Gram-positive and Gram-negative bacteria and interacts with lung surfactant protein D. Eur J Immunol (2003) 33:2327-36. doi:10.1002/eji.200323972

26. Haukioja A, Loimaranta V, Tenovuo J. Probiotic bacteria affect the composition of salivary pellicle and streptococcal adhesion in vitro. Oral Microbiol Immunol (2008) 23:336-43. doi:10.1111/j.1399-302X.2008.00435.X

27. Rosenstiel P, Sina C, End C, Renner M, Lyer S, Till A, et al. Regulation of DMBT1 via NOD2 and TLR4 in intestinal epithelial cells modulates bacterial recognition and invasion.J Immunol (2007) 178:8203-11. doi:10.4049/jimmunol.178.12.8203

28. Jumblatt MM, Imbert Y, Young WW Jr, Foulks GN, Steele PS, Demuth DR. Glycoprotein 340 in normal human ocular surface tissues and tear film. Infect Immun (2006) 74:4058-63. doi:10.1128/IAI.01951-05

29. Nagashunmugam T, Malamud D, Davis C, Abrams WR, Friedman HM. Human submandibular saliva inhibits human immunodeficiency virus type 1 infection by displacing envelope glycoprotein gp 120 from the virus. J Infect Dis (1998) 178:1635-41. doi:10.1086/314511

30. Hartshorn KL, White MR, Mogues T, Ligtenberg T, Crouch E, Holmskov U. Lung and salivary scavenger receptor glycoprotein- 340 contribute to the host defense against influenza A viruses. Am J Physiol Lung Cell Mol Physiol (2003) 285:L1066-76. doi:10.1152/ajplung.00057.2003

31. Holmskov U, Mollenhauer J, Madsen J, Vitved L, Gronlund J, Tornoe I, et al. Cloning of gp-340, a putative opsonin receptor for lung surfactant protein D. Proc Natl Acad Sci U S A (1999) 96:10794-9. doi:10.1073/pnas.96.19.10794

32. Mollenhauer J, Herbertz S, Holmskov U, Tolnay M, Krebs I, Merlo A, et al. DMBT1 encodes a protein involved in the immune defense and in epithelial differentiation and is highly unstable in cancer. Cancer Res (2000) 60:1704-10.

33. Mollenhauer J, Herbertz S, Helmke B, Kollender G, Krebs I, Madsen J, et al. Deleted in malignant brain tumors 1 is a versatile mucin-like molecule likely to play a differential role in digestive tract cancer. Cancer Res (2001) 61:8880-6.

34. Kang W, Nielsen O, Fenger C, Madsen J, Hansen S, Tornoe I, et al. The scavenger receptor, cysteine-rich domain-containing molecule gp-340 is differentially regulated in epithelial cell lines by phorbol ester. Clin Exp Immunol (2002) 130:449-58. doi:10.1046/j.1365-2249.2002.01992.x

35. Stoddard E, Cannon G, Ni H, Kariko K, Capodici J, Malamud D, et al. gp340 expressed on human genital epithelia binds HIV-1 envelope protein and facilitates viral transmission. JImmunol (2007) 179:3126-32. doi:10.4049/ jimmunol.179.5.3126

36. Schulz BL, Oxley D, Packer NH, Karlsson NG. Identification of two highly sialylated human tear-fluid DMBT1 isoforms: the major high-molecular-mass glycoproteins in human tears. Biochem J (2002) 366:511-20. doi:10.1042/ bj20011876

37. Reichhardt MP, Jarva $\mathrm{H}$, de Been M, Rodriguez JM, Jimenez Quintana E, Loimaranta V, et al. The salivary scavenger and agglutinin in early life: diverse roles in amniotic fluid and in the infant intestine. J Immunol (2014) 193:5240-8. doi:10.4049/jimmunol.1401631

38. Sonesson M, Ericson D, Kinnby B, Wickstrom C. Glycoprotein 340 and sialic acid in minor-gland and whole saliva of children, adolescents, and adults. Eur J Oral Sci (2011) 119:435-40. doi:10.1111/j.1600-0722.2011.00879.x

39. Ligtenberg AJ, Karlsson NG, Veerman EC. Deleted in malignant brain tumors-1 protein (DMBT1): a pattern recognition receptor with multiple binding sites. Int J Mol Sci (2010) 11:5212-33. doi:10.3390/ijms1112521

40. Wu Z, Van Ryk D, Davis C, Abrams WR, Chaiken I, Magnani J, et al. Salivary agglutinin inhibits HIV type 1 infectivity through interaction with viral glycoprotein 120. AIDS Res Hum Retroviruses (2003) 19:201-9. doi:10.1089/088922203763315704
41. Jonasson A, Eriksson C, Jenkinson HF, Kallestal C, Johansson I, Stromberg N. Innate immunity glycoprotein gp-340 variants may modulate human susceptibility to dental caries. BMC Infect Dis (2007) 7:57. doi:10.1186/1471-2334-7-57

42. Mollenhauer J, Holmskov U, Wiemann S, Krebs I, Herbertz S, Madsen J, et al. The genomic structure of the DMBT1 gene: evidence for a region with susceptibility to genomic instability. Oncogene (1999) 18:6233-40. doi:10.1038/ sj.onc. 1203071

43. Mollenhauer J, Muller H, Kollender G, Lyer S, Diedrichs L, Helmke B, et al. The SRCR/SID region of DMBT1 defines a complex multi-allele system representing the major basis for its variability in cancer. Genes Chromosomes Cancer (2002) 35:242-55. doi:10.1002/gcc.10115

44. Mollenhauer J, Helmke B, Muller H, Kollender G, Lyer S, Diedrichs L, et al. Sequential changes of the DMBT1 expression and location in normal lung tissue and lung carcinomas. Genes Chromosomes Cancer (2002) 35:164-9. doi:10.1002/gcc.10096

45. Ligtenberg AJ, Veerman EC, Nieuw Amerongen AV. A role for Lewis a antigens on salivary agglutinin in binding to Streptococcus mutans. Antonie Van Leeuwenhoek (2000) 77:21-30. doi:10.1023/A:1002054810170

46. Eriksson C, Frangsmyr L, Danielsson Niemi L, Loimaranta V, Holmskov $\mathrm{U}$, Bergman T, et al. Variant size- and glycoforms of the scavenger receptor cysteine-rich protein gp-340 with differential bacterial aggregation. Glycoconj $J(2007)$ 24:131-42. doi:10.1007/s10719-006-9020-1

47. Reid KB, Porter RR. Subunit composition and structure of subcomponent C1q of the first component of human complement. Biochem J (1976) 155:19-23. doi:10.1042/bj1550019

48. Sellar GC, Blake DJ, Reid KB. Characterization and organization of the genes encoding the A-, B- and C-chains of human complement subcomponent C1q. The complete derived amino acid sequence of human C1q. Biochem J (1991) 274(Pt 2):481-90. doi:10.1042/bj2740481

49. Kojouharova MS, Tsacheva IG, Tchorbadjieva MI, Reid KB, Kishore U. Localization of ligand-binding sites on human Clq globular head region using recombinant globular head fragments and single-chain antibodies. Biochim Biophys Acta (2003) 1652:64-74. doi:10.1016/j.bbapap.2003.08.003

50. Ligtenberg AJ, Bikker FJ, De Blieck-Hogervorst JM, Veerman EC, Nieuw Amerongen AV. Binding of salivary agglutinin to IgA. Biochem J (2004) 383:159-64. doi:10.1042/BJ20040265

51. White MR, Crouch E, Vesona J, Tacken PJ, Batenburg JJ, Leth-Larsen R, et al. Respiratory innate immune proteins differentially modulate the neutrophil respiratory burst response to influenza A virus. Am J Physiol Lung Cell Mol Physiol (2005) 289:L606-16. doi:10.1152/ajplung.00130.2005

52. White MR, Crouch E, van Eijk M, Hartshorn M, Pemberton L, Tornoe I, et al. Cooperative anti-influenza activities of respiratory innate immune proteins and neuraminidase inhibitor. Am J Physiol Lung Cell Mol Physiol (2005) 288:L831-40. doi:10.1152/ajplung.00365.2004

53. Jarva H, Jokiranta TS, Hellwage J, Zipfel PF, Meri S. Regulation of complement activation by C-reactive protein: targeting the complement inhibitory activity of factor $\mathrm{H}$ by an interaction with short consensus repeat domains 7 and 8-11. J Immunol (1999) 163:3957-62.

54. Deban L, Jarva H, Lehtinen MJ, Bottazzi B, Bastone A, Doni A, et al. Binding of the long pentraxin PTX3 to factor H: interacting domains and function in the regulation of complement activation. J Immunol (2008) 181:8433-40. doi:10.4049/jimmunol.181.12.8433

55. Fox S, Ryan KA, Berger AH, Petro K, Das S, Crowe SE, et al. The role of C1q in recognition of apoptotic epithelial cells and inflammatory cytokine production by phagocytes during Helicobacter pylori infection. J Inflamm (Lond) (2015) 12:51. doi:10.1186/s12950-015-0098-8

56. Stone MA, Mayberry JF, Baker R. Prevalence and management of inflammatory bowel disease: a cross-sectional study from central England. EurJ Gastroenterol Hepatol (2003) 15:1275-80. doi:10.1097/00042737-200312000-00004

57. Van Limbergen J, Russell RK, Drummond HE, Aldhous MC, Round NK, Nimmo ER, et al. Definition of phenotypic characteristics of childhood-onset inflammatory bowel disease. Gastroenterology (2008) 135:1114-22. doi:10.1053/j.gastro.2008.06.081

58. Bak-Romaniszyn L, Szala A, Sokolowska A, Mierzwa G, Czerwionka-Szaflarska M, Swierzko AS, et al. Mannan-binding lectin deficiency in pediatric patients with inflammatory bowel disease. Scand J Gastroenterol (2011) 46:1275-8. do i: $10.3109 / 00365521.2011 .594087$ 
59. Aittoniemi J, Pertovaara M, Hulkkonen J, Pasternack A, Hurme M, Laippala $\mathrm{P}$, et al. The significance of mannan-binding lectin gene alleles in patients with primary Sjögren's syndrome. Scand J Rheumatol (2002) 31:362-5. doi:10.1080/030097402320817095

60. Slade JD, Luskin AT, Gewurz H, Kraft SC, Kirsner JB, Zeitz HJ. Inherited deficiency of second component of complement and HLA haplotype A10,B18 associated with inflammatory bowel disease. Ann Intern Med (1978) 88:796-8. doi:10.7326/0003-4819-88-6-796

61. Freeman HJ. Hereditary angioneurotic edema and familial Crohn's disease. Can J Gastroenterol (2000) 14:337-9.

62. Farkas H, Gyeney L, Nemesanszky E, Kaldi G, Kukan F, Masszi I, et al. Coincidence of hereditary angioedema (HAE) with Crohn's disease. Immunol Invest (1999) 28:43-53. doi:10.3109/08820139909022722

63. Kolho KL, Paakkanen R, Lepistö AL, Wennerstom A, Meri S, Lokki ML. Novel associations between major histocompatibility complex and pediatric-onset inflammatory bowel disease. J Pediatr Gastroenterol Nutr (2015). doi:10.1097/ MPG.0000000000000984

64. Sandahl TD, Kelsen J, Dige A, Dahlerup JF, Agnholt J, Hvas CL, et al. The lectin pathway of the complement system is downregulated in Crohn's disease patients who respond to anti-TNF-alpha therapy. JCrohns Colitis (2014) 8:521-8. doi:10.1016/j.crohns.2013.11.007

65. Diegelmann J, Czamara D, Le Bras E, Zimmermann E, Olszak T, Bedynek A, et al. Intestinal DMBT1 expression is modulated by Crohn's disease-associated IL23R variants and by a DMBT1 variant which influences binding of the transcription factors CREB1 and ATF-2. PLoS One (2013) 8:e77773. doi:10.1371/ journal.pone.0077773

66. Kim TH, Lee SH, Lee HM, Jung HH, Lee SH, Cho WS, et al. Increased expression of glycoprotein 340 in the ethmoid sinus mucosa of patients with chronic sinusitis. Arch Otolaryngol Head Neck Surg (2007) 133:1111-4. doi:10.1001/ archotol.133.11.1111
67. Renner M, Bergmann G, Krebs I, End C, Lyer S, Hilberg F, et al. DMBT1 confers mucosal protection in vivo and a deletion variant is associated with Crohn's disease. Gastroenterology (2007) 133:1499-509. doi:10.1053/j. gastro.2007.08.007

68. Hamm CM, Reimers MA, McCullough CK, Gorbe EB, Lu J, Gu CC, et al. NOD2 status and human ileal gene expression. Inflamm Bowel Dis (2010) 16:1649-57. doi:10.1002/ibd.21208

69. Muller H, End C, Weiss C, Renner M, Bhandiwad A, Helmke BM, et al. Respiratory deleted in malignant brain tumours 1 (DMBT1) levels increase during lung maturation and infection. Clin Exp Immunol (2008) 151:123-9. doi:10.1111/j.1365-2249.2007.03528.x

70. Madsen J, Sorensen GL, Nielsen O, Tornoe I, Thim L, Fenger C, et al. A variant form of the human deleted in malignant brain tumor 1 (DMBT1) gene shows increased expression in inflammatory bowel diseases and interacts with dimeric trefoil factor 3 (TFF3). PLoS One (2013) 8:e64441. doi:10.1371/ journal.pone.0064441

71. Aamann L, Vestergaard EM, Gronbaek H. Trefoil factors in inflammatory bowel disease. World J Gastroenterol (2014) 20:3223-30. doi:10.3748/wjg.v20. i12.3223

Conflict of Interest Statement: The authors declare that the research was conducted in the absence of any commercial or financial relationships that could be construed as a potential conflict of interest.

Copyright (c) 2016 Reichhardt and Meri. This is an open-access article distributed under the terms of the Creative Commons Attribution License (CC BY). The use, distribution or reproduction in other forums is permitted, provided the original author(s) or licensor are credited and that the original publication in this journal is cited, in accordance with accepted academic practice. No use, distribution or reproduction is permitted which does not comply with these terms. 